\title{
Farmers' Attitudes towards Participation in short Food Supply Chains: Evidence from a Chinese field research
}

\author{
Atitudes dos agricultores em relação à participação em cadeias curtas de \\ abastecimento de alimentos: evidências de uma pesquisa de campo na China
}

\author{
Meng Wang ${ }^{1}$ \\ Vikas Kumar ${ }^{2}$ \\ Ximing Ruan ${ }^{3}$ \\ Daiane Mulling Neutzling ${ }^{4}$
}

\begin{abstract}
As the industrialized agro-food supply systems have been commonly criticized for their adverse environmental and social impact, Short food supply chains have emerged as a promising sustainable alternative. Given that the history of SFSCs is relatively short, the majority of empirical evidences is from developed countries, and existing studies on SFSCs in developing country context are rather limited. Therefore, this study aims to investigate the farmers' attitudes towards participating in SFSCs by conducting a field research in China. Semi-structured interviews were implemented with eight participants selected from a local farmer market as a pilot study. The social and economic reasons are found to be the main motivations of Chinese farmers participating in SFSCs. However, none of these interviewed participants are aware of the environmental effects of SFSCs. Moreover, the findings were cross-compared with existing studies conducted in developed countries. It was found that Chinese farmers participating in SFSCs are mainly passive choice, as they lack of relevant knowledge and governmental support.
\end{abstract}

Keywords: Short Food Supply Chain.Farmer Market. Semi-structured Interview. Pilot Study.

\section{Resumo}

A industrialização dos sistemas de suprimentos agroalimentares tem sido comumente criticada pelos diversos impactos ambientais e sociais. Por esse motivo, as chamadas cadeias curtas de suprimentos de alimentos, ou "short food supply chains" (SFSC), surgiram como uma alternativa sustentável promissora. Dado que a história das SFSCs é relativamente curta, a maioria das evidências empíricas é de países desenvolvidos, e os estudos existentes sobre SFSCs no contexto dos países em desenvolvimento são bastante limitados. Portanto, este estudo tem como objetivo investigar as atitudes dos agricultores em relação à participação em SFSCs, realizando uma pesquisa de campo na China. Entrevistas semiestruturadas foram implementadas com oito participantes, selecionados de um mercado de agricultores locais, como um estudo piloto. As razões sociais e econômicas são as principais motivações dos agricultores chineses que participam das SFSCs. No entanto, nenhum dos participantes entrevistados está ciente dos efeitos ambientais das SFSCs. Além disso, os resultados foram cruzados com estudos existentes em países desenvolvidos. Verificou-se que os agricultores chineses que participam em SFSCs são, principalmente, escolhas passivas, uma vez que não possuem conhecimento relevante nem apoio governamental.

Palavras-chave: Short Food Supply Chain. Mercado de agricultores. Entrevista semiestruturada. Estudopiloto.

PhD student at Bristol Business School. Afiliação: University of the West of England, Bristol Bristol Business School, País: Reino Unido. Email: Meng2.Wang@live.uwe.ac.uk.

2 Professor of Operations and Suppy Chain Management - Faculty of Business and Law. Afiliação: University of the West of England, Bristol Bristol Business School. Email: Vikas.Kumar@uwe.ac.uk

Senior Lecturer: Strategy \& Operations Management - Faculty of Business and Law. Afiliação: University of the West of England, Bristol Bristol Business School. Email: ximing.Ruan@uwe.ac.uk

4 Doutorado em Administração pela Universidade Federal do Rio Grande do Sul, Brasil(2014)

Professora Assistente III da Universidade de Fortaleza (UNIFOR). País: Brasil. Afiliação: PPGA UNIFOR. Email: d.neutzling@unifor.br 


\section{Introduction}

Owing to its ability to sufficiently mitigate the food crisis with modernistic large-scale production, the industrialized agro-food supply chain has achieved incredible success in the past decades (Roth et al., 2008). However, the reputation of the standardized food in this industrialized agriculture system has been deteriorating (Macartney, 2008). It has been increasingly criticized for the adverse environmental and social impact (Mastronardi et al., 2015) and safety issues (Llazo, 2014). The massive production feature of this traditional food supply system has raised widespread concerns about its unsustainability and harms to the environment, such as excessive land use, pollution of soils and water, and exhaust emissions (Bazzani and Canavari, 2013). Moreover, from the farmers' perspective, the increasing cost to maintain massive production and consumers' changing attitudes towards industrialized food both further compress the economic margin, leading to increased pressure on farmers' incomes (Renting et al., 2003). Meanwhile, the lack of information flow can cause dramatic decrease in the profit of farmers. The cost-price squeeze of commodity production also threatens farmers' revenue (Berti and Mulligan, 2016).

Owing to all these disadvantages of current industrialized food supply system, there has been a wide consensus on improving the sustainability in food supply system (Forssell and Lankoski, 2015). Several alternative forms of food supply chain are hence proposed, which abandons the main features of traditional food chain, such as massive production and standardized organisation (Higgins et al., 2008). Short Food Supply Chains (SFSCs) is one of those sustainable alternatives to the conventional food supply chains (Chiffoleau et al., 2016). It is a type of Alternative Food Networks (AFNs) that operates as a local food system, and short-circuits the traditional long food supply chains. While there hasn't been a consensus on a unified definition of SFSCs (Marsden et al., 2000; Giarè and Giuca, 2012; Kneafsey et al., 2013), it generally refers to any forms of re-joining farmers with consumers, with minimized number of intermediaries (Ilbery and Maye, 2005). Instead of solely exchanging a product, this direct connection between producers and consumers shares additional information about knowledge, value, meaning of the product, and producer and consumer themselves (Marsden et al., 2000). As a promising sustainable alternative to the conventional food supply chains, some research evidences have shown that SFSCs have a close linkage with sustainability. For instance, economically, farmers can regain the profit shared by intermediates, and hence improve their livelihoods (Hinrichs, 2000). Environmentally, it can improve biodiversity and reduce environmental pollutions (Canfora, 2016). Socially, more employment opportunities and a better visibility can be obtained with SFSCs (Marino et al., 2013). Meanwhile, farmers can re-socialize with consumers (Marsden et al., 2000).

According to the literature review conducted by Kumar et al. (2018), the majority of existing studies on SFSCs has been conducted in developed countries. A country-based classification of the reviewed 55 studies is shown in Figure 01.

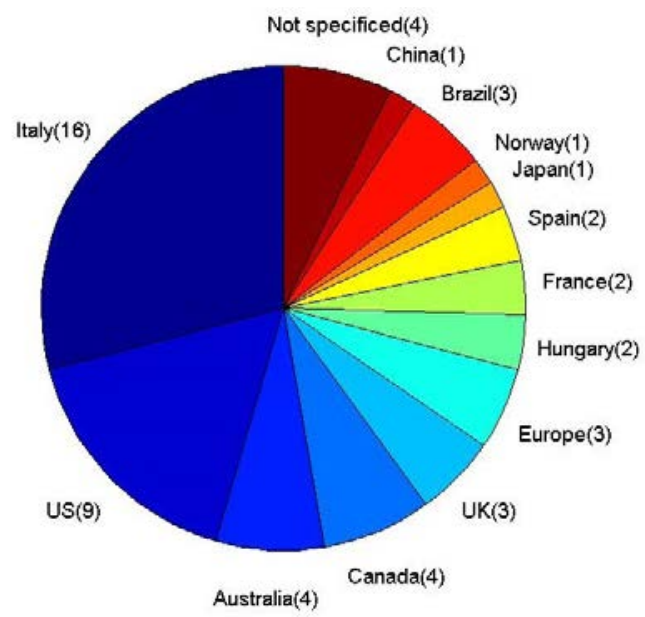

Figure 01 - Country Classification of Publications

Source: Prepared by the Authors 
It can be noted that Italy has the largest number of publications (16), which occupies $29.09 \%$ among all countries, and $55.17 \%$ among EU countries. This phenomenon correlates with the fact that Italy is one of the largest agricultural producers in EU. Moreover, 29 studies $(52.72 \%)$ were conducted in EU countries, which indicated that EU researchers have larger interest in adopting these new modes of food supply system. Furthermore, an interesting difference between developing and developed countries was also noted. Brazil and China were the only two developing countries that have research on SFSCs, with a total of 4 publications. Meanwhile, instead of any specific types of SFSCs, such as FMs and CSA, these studies all focused on the general form of SFSCs and AFNs. This indicates that such studies in developing country context just emerge and are rather limited.

Although SFSCs have gained increasing research interest, it should be noted that as a newly emerged form of food supply system, farmers' attitude towards the participation is a vital measure of its practical significance. While several studies have confirmed that participating in SFSCs can increase farmers' profits and hence improve their livelihoods, whether they may be willing to switch their selling mode is still under debate. Extensive external and internal factors can affect their decision, most notably, the convenience to switch and the culture and regional factors. Given that the existing studies on SFSCs in developing countries are rather limited, this study hence proposes to investigate the farmers' attitudes towards participating in SFSCs by conducting a field research in China. This study can potentially help to identify the challenges of SFSCs adoption in China and facilitate the development of corresponding mitigation solutions. While SFSCs consists of a wide variety of different forms, namely farmer market, farmer shop, community supported agriculture, etc., farmer market was selected as the research target in this study, as it is the most typical form of SFSCs and has been investigated in many existing studies (Renting et al., 2003).

The next sections address the following topics: the methodology; the results and discussion of this study; and the conclusion.

\section{Methodology}

A field research was conducted to facilitate the data collection for this study. The research venue was selected to be the Xinxiang city of Henan province. The reason of choosing this location is because it has a rich variety of agriculture products and is the largest agriculture province in China, with 6.825 million hectares of arable land (China Through A Lens, 2001). 29 new farmer markets and other forms of SFSCs have been built in the selected city in the last two years (Rural Planning Bureau of Xinxiang, 2017). This increase is expected to cause a dramatic growth of SFSCs participation. These farmer markets with different socialeconomic conditions are distributed throughout the city. One medium sized farmer market was selected to serve as the data collection venue for this pilot study, as it is located in an urban-rural connected area, and has a notable number of consumers and farmers, as illustrated in Figure 02.

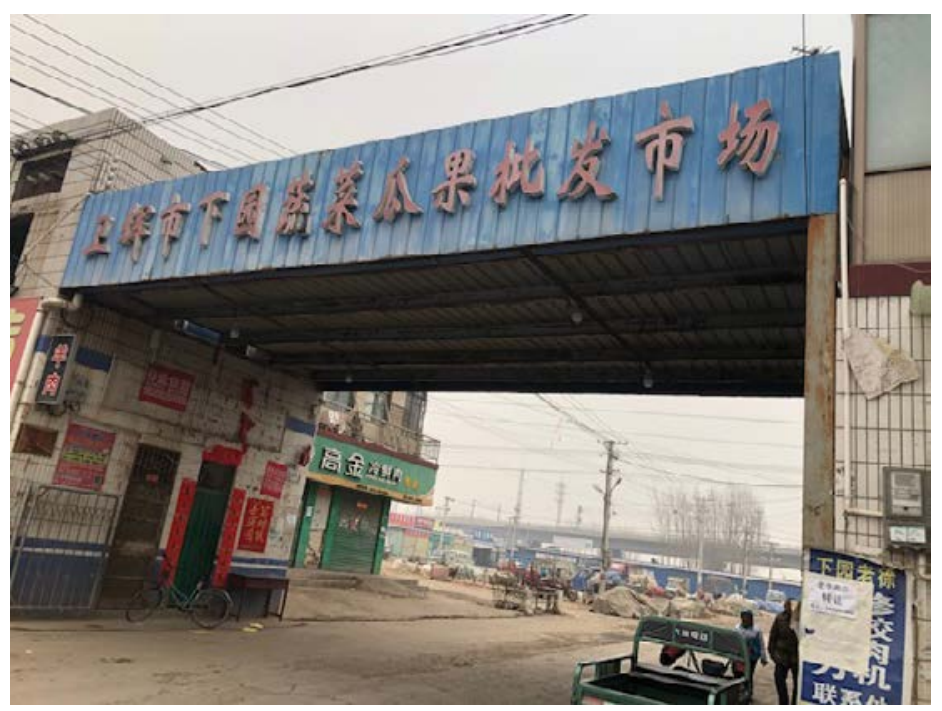

Figure 02 - Entrance of the Data Collection Venue Source: Prepared by the Authors 
In this study, the field research was employed to investigate the SFSCs and its linkage with sustainability. The farmer participants were randomly recruited from the chosen farmer market to take part in the study on site at a convenient time of the day. Only the farmers who sold fresh food were considered eligible for the study. This resulted in the final sample size of eight farmer participants. These participants were notified that the interview will be voice-recorded and aim is to explore their motivations and opinions about SFSCs and its linkage with sustainability. The major interview questions could be divided into two parts. The first part concerning the general information of farmers (the demographic characteristics of farmers, their produce variety, the distance from their land to the market). In the second part of the interview, the open-ended questions were designed and asked to collect information about their motivations towards taking part in SFSCs and their opinions about sustainable agriculture. The interview transcripts were translated and coded in English using an inductive coding strategy and analysed using the triple bottom line principles of sustainability.

\section{Results and Discussion}

\subsection{Descriptive results}

As shown in Table01, it can be noted that the majority of the interviewed farmers (62.5\%) were female. The average age of these participants were about $56 \mathrm{yrs}$. The oldest participant was $64 \mathrm{yrs}$ old, while three youngest participants are all in 50s. Meanwhile, none of these participants were highly educated, with the highest education level to be the secondary school. All three male farmers were less educated, as two of them graduated from primary school and another one never received any education before. Among the five female farmers, only one graduated from primary school, and all other five went to secondary school. Meanwhile, it is also found that the interviewed participants were all professional farmers and have been engaged in farming since their early 20 s. Moreover, their farms are all family-dominated, without any hired co-workers. Their farms are managed either by their own or with their spouse.

Table 01 - Interviewed Farmer Demographics

\begin{tabular}{c|c|c|c|c|c|c}
\hline ID & Gender & Age & Education & Length of farming & Income (£/year) & Farm type \\
\hline 1 & Female & $50-60$ & Secondary & $30+$ years & 5500 & traditional \\
\hline 2 & Female & $50-60$ & Secondary & $30+$ years & 4600 & traditional \\
\hline 3 & Female & $40-50$ & Primary & $30+$ years & 6000 & traditional \\
\hline 4 & Female & $40-50$ & Secondary & $20+$ years & 8400 & greenhouse \\
\hline 5 & Female & $50-60$ & Secondary & $30+$ years & 2300 & traditional \\
\hline 6 & Male & $60+$ & None & $40+$ years & 4600 & traditional \\
\hline 7 & Male & $60+$ & Primary & $40+$ years & 4000 & traditional \\
\hline 8 & Male & $60+$ & Primary & $40+$ years & 2300 & traditional \\
\hline
\end{tabular}

Source: Prepared by the Authors

The main products are very similar among these interviewed farmers. The majority of them plants cabbage, carrot, spinach, and tomato. The only exception is one farmer that owns a greenhouse. With the temperature control function of the greenhouse, she grows cucumber as the main produce. The monthly revenue also reflects this difference, as most farmers can earn about $£ 400$ to $£ 500$ per month, while the farmer with greenhouse can earn up to $£ 900$ per month. However, it should be noted that the development of a greenhouse demands the permission from local government and a one-off payment of approximately $£ 10,000$. Therefore, this type of greenhouse culture may not be suitable for all farmers.

Meanwhile, all these participants use trailers to transport their products between their farms and the market. The average covered distance is approximately $5 \mathrm{~km}$, with a standard deviation of $4.4 \mathrm{~km}$. These farmers are all coming from nearby villages. It should be noted that selling in the selected farmer market requires an entrance fee, which can cost approximately $£ 300$ per year, and is free to farmers living in the neighborhood of the market. Among the eight interviewed participants, only two of them need to pay the fee, 
while all other six farmers are entitled to free entry. Therefore, this farmer market is the first choice of all the interviewed farmers as they prefer the convenience and shopping atmosphere at this venue.

Along with the descriptive analysis of the interviewed farmers, some open-ended questions were also designed to gather these participants' opinions on some specific aspects. These questions were designed in accordance with the three pillars of sustainability to facilitate the evaluation into the linkage between SFSCs and sustainability in the Chinese context.

\subsection{Social}

The questions in this section mainly consist of three aspects, which concerns on the food quality, the shopping atmosphere, and the social connection with customers and fellow farmers, respectively.

It was found that all participated farmers claimed their agricultural products have better quality than those sold in supermarkets. Although they also use pesticides to prevent plant diseases and insect pests, they all confirmed the minimum use of pesticides during the initial several months, and they have ceased to use them a long period before selling these products. During the interview, they also showed solid confidence in their food safety as they stated that "my family eats the same agricultural products as I sell". However, it should be noted that although they have devoted to improve food safety, there is still a lack of government monitoring on this issue. Among the eight interviewed farmers, only the participant that owns a greenhouse have received regular spot check test from the government, while all other farmers can directly sell their agricultural products without any regulation. This phenomenon also reflects some mess in the agricultural system in China. As developing the greenhouse demands government approval, it is hence much easier to locate the farms and monitor the quality of the produce. However, with the increasing number of migrant workers moving away from rural area, it is hence difficult to trace the owners and status of certain farm lands. Therefore, monitoring these traditional farms is a more sophisticated issue.

Meanwhile, the friendly shopping atmosphere is another important factor that has been reported by all interviewed farmers. These participants all confirmed that the direct interaction with customers is a significant motivation that drives them to participate in SFSCs. They all stated that "talking with customers is really enjoyable, as we can share information on many things". They all enjoy the chatting and relaxed shopping atmosphere at this farmer market. It should also be noted that three farmers have been involved with traditional form of food supply system before, in which wholesalers will come to their farms to procure agricultural products at large scale. Although they all admitted that selling to wholesalers is more convenient, they still prefer selling at the farmer market as they can enjoy the social communications with customers.

Along with the social connection with customers, another factor that motivates these farmers to participate in SFSCs is the communication and relationship with other farmers. According to these interviewed farmers, they can share product information and negotiate on a unified price of certain products at this farmer market. Through the direct communications with fellow farmers, they can gain more information on the farming status of nearby villages, the revenue of other agricultural products, and reduce the risk of vicious pricing. Moreover, they can also share experience on farming and increase the potential of collaboration through developing personal relationship with fellow farmers.

\subsection{Economic}

Along with the questions focusing on the social aspect of participating in SFSCs, the economic pillar was also addressed with some designated questions. These questions mainly concern on the changing tendency of revenue in recent years, and the profits gained at farmer market compared with selling to wholesalers.

It was found that the higher revenue of direct sale is another important factor that motivates these farmers to join SFSCs. Among the interviewed participants, only the farmer that owns a greenhouse receives satisfying revenue, and maintains a leveled profit over the past five years. Meanwhile, all other seven traditional farmers indicated a rapid decreasing profit over the same period, as they stated "it's becoming more and more difficult to earn some money". The major reason to this decreasing revenue is the rapidly increasing number of farmers. According to the interviewed farmers, owing to some relevant government 
policy and support, the revenue of farming reached its peak about five years ago which can be approximately twice the profit of this year. Many people living in rural area have hence been attracted to farming since then. The fierce competition and the involvement of wholesalers has caused vicious pricing and led to the decreasing profits in recent years. The wholesalers tend to take advantage of the lack of pricing information and hence steal the majority of the profit from farmers, as indicated by the interviewed farmers, "the price of selling to wholesalers is much lower than selling directly to customers". Although the convenience of selling to wholesalers is widely admitted by the interviewed farmers, they all preferred to directly sell to customers regain the profits shared by wholesalers and hence increase the total revenue.

Moreover, another significant benefit of selling at farmer market is the avoidance of vicious pricing. Since the farmers all coming from nearby villages and know each other, they can negotiate on a unified price of certain products. Therefore, they can increase their profits and minimize the risk of vicious pricing.

\subsection{Environmental}

The designated questions focusing on the environmental pillar mainly concern on the biodiversity, pesticide usage and food mile, respectively.

It was found that although these farmers plant a wide variety of agricultural products, none of them have ever heard of biodiversity before. Their major motivation of farming different kinds of products is to increase profit and reduce the risk of low price of one or two agricultural products in certain periods. Thus, the reason of farming several kinds of agricultural products is mainly economic and experience oriented, instead of concerning on the environmental protection. Therefore, it can be noted that owing to the limited education and insufficient government propaganda, Chinese farmers have rather limited knowledge on environmental sustainability, as they stated "I have never heard of environmental sustainability before".

Meanwhile, the usage of pesticide can also reflect the same issue. While all farmers demonstrated that they have minimized the usage of pesticide, their main concentration is on food safety, as none of the interviewed farmers have considered the environmental pollution caused by pesticide before. Moreover, although some farmers have consulted instructions to decide pesticide amount, these interviewed participants indicated that their determination on pesticide usage is mainly based on experience, as they stated "I have been farming for so many years, I know how many pesticide should be used". This vagueness on the pesticide usage also reflects the farmers' unconscious on the environmental pollution caused by pesticide.

As all interviewed farmers live in nearby villages, their covered food miles are relatively small. Only two participants travelled over $10 \mathrm{~km}$, and all other farmers live less than $5 \mathrm{~km}$ away from the market. According to these participants, this close geographic distance is also an important factor that motivates them to choose this farmer market. As their main transportation is via trailers, long travel distance is hence unrealistic for them. Although there are other farmer markets in the city, they prefer this market to minimize the travel distance and reduce the efforts of moving agricultural products. Therefore, it can be noted that although their original motivation of selling at nearby farmer market is not caused by environmental concern, the final outcome has resulted in the minimized food miles.

\subsection{Comparison with Existing Studies}

As this study was conducted in China, a major agricultural-export developing country, it would hence be beneficial to compare the findings from this research with other existing studies, which are mainly implemented in developed countries. This comparison can facilitate the investigation into the impacts of cultural and livelihood factors on farmers' motivation towards participating in SFSCs.

From the conducted pilot study, it can be noted that all interviewed male participants are over 60 , while all female farmers are aged between 40 and 60 . This phenomenon is not restricted to the interviewed farmers, as the majority of sellers at the farmer market are younger females. Although increasing the involvement of females in SFSCs can benefit from improved food security, more pleasant shopping atmosphere, and improved gender equality (Zirham and Palomba, 2015; Zirham and Palomba, 2016), it should be noted that farming still 
tends to be a male-dominated activity in developed countries. As the gender proportion and age tendency are rather distinct from existing studies, the cause of this phenomenon was further investigated during the interview. It was found that younger males in these families are mainly migrant workers, who moved to larger cities to work in construction sites or factories to earn extra income. It should be noted that in China, farm machinery is still not available to the majority of farmers. Therefore, all farming related activities, such as planting and harvesting, are still achieved by farmers manually. The lack of technology advancements have hence restricted the size of farming, as most farms in China are either medium or small sized. Moreover, it was also found that the governmental support on farming is very limited. Thus, the income depending solely on farming is insufficient for a Chinese family, especially when their children need to study in college. Younger males working as migrant farmers are hence a common solution to earn extra income and financially support the family (Lu and Xia, 2016). As farming is more profitable in developed countries, it can hence be noted that the livelihood of Chinese farmers is tougher. Moreover, the large amount of migrant workers has also caused multiple social issues, mainly associated with their poor working and living conditions (Carrillo, 2004). Thus, increasing the profit of farming in China is a prominent issue that needs government support and guidance.

Meanwhile, another huge difference in the farmer demographic is the education level, as the perceived education of farmers in China is significantly lower than other reported studies in developed countries. The lack of education also reflects in the absence of sustainable agriculture, the usage of pesticide, and the ignorance of biodiversity (Chen and Zheng, 2016). It can be noted that in developed countries farmers' motivations of participating in SFSCs are mainly spontaneous, such as reducing energy consumption (Smith, 2008), improving biodiversity (Canfora, 2016), and regaining the profits shared by intermediates (Benedek et al., 2017). However, although Chinese farmers enjoyed some typical advantages of SFSCs, such as increased profit and direct communication with customers, their participations in SFSCs are more like a passive choice, as they tend to have rather limited knowledge of SFSCs and its benefits.

Along with the demographic difference, the farmers' opinions on the three sustainability pillars of SFSCs also differ to some extent. It should be noted that the earliest research investigating the social sustainability of SFSCs was implemented by Sage in 2003, when he explored the benefits of direct interactions in SFSCs. Since then, the social benefits of SFSCs have been extensively investigated. The most widely acknowledged social benefits of SFSCs in existing studies are identified as the improved food quality and security (Hinrichs, 2000; Marsden et al., 2000; Hinson and Bruchhaus, 2008; Smith, 2008; Jones and Bhatia, 2011; Bimbo et al., 2015; Engelseth, 2016; Leiper and Sather, 2017), additional employment opportunities (Ilbery and Maye, 2005; Sgroi et al., 2014; Falguieres et al., 2015; Tudisca et al., 2015; Mundler and Laughrea, 2016;Rover et al., 2017), and the regained consumers' trust (Hinson and Bruchhaus, 2008; O'Kane and Wijaya, 2015; Giampietri, 2016; Giampietri, 2018). Meanwhile, the friendly shopping atmosphere (Hinson and Bruchhaus, 2008; Watts et al., 2011; Zirham and Palomba, 2015; Benedek et al., 2017; Leiper and Sather, 2017) and the social connection with customers and fellow farmers (Beckie et al., 2012) are also noted as the improved social sustainability of SFSCs. Based on the results from the conducted pilot study, it can be noted that a high correlation can be found on the farmers' opinions on this social pillar. The interviewed Chinese farmers also approve the majority of these social benefits, most notably, the improved food quality, the friendly shopping atmosphere, and the social connections with other people. While none of these interviewed farmers have directly approved the benefit of regaining consumers' trust, they have indicated that they have many repeat customers, which shows the underlying consumers' trust on their products. However, it should be noted that the potential of creating more employment opportunities is denied by all the interviewed farmers. This could be caused by the characteristics of Chinese farms, as they tend to be smaller scale and rarely adopted any farming machineries. Thus, these Chinese farms are mainly operated and maintained by the farmers and their spouses, restricting the potential of hiring additional labors. Nonetheless, it can still be noted that the Chinese farmers' opinions on the social pillar of SFSCs are highly correlated with the existing studies conducted in developed countries.

Owing to the difficulty in measuring the economic effects of SFSCs, the improvements in economic sustainabilityare less evident than the social pillar. Thus, the acknowledged economic benefits of SFSCs are rather limited. The most typical economic benefit is identified as the regained profits shared by intermediates 
(Hinrichs, 2000; Marsden et al., 2000; Smith, 2008; D’Amico et al., 2014; Sgroi et al., 2014; Tudisca et al., 2015; Balázs et al, 2016; Engelseth, 2016; Demartini et al., 2017; Leiper and Sather, 2017). This is the most widely acknowledged economic feature of SFSCs in the existing studies. Meanwhile, some researchers (Watts et al., 2011; Smith, 2008; Migliore et al., 2015; Balázs et al, 2016; Benedek et al., 2017; Elghannam et al., 2017) also found that SFSCs can have a positive influence on local economy. Although the improvements in economic sustainability are fewer than the social benefits, a high correlation was also found between the interviewed farmers and these existing studies. While the increased profits of SFSCs are also approved by these Chinese farmers, none of them have felt contributing to local economy. This could be caused by the lack of governmental propaganda. Moreover, a unique finding of this study is that Chinese farmers admitted participating in SFSCs can reduce the risk of vicious pricing. This phenomenon hasn't been discussed in the existing studies before. This could be also caused by the characteristics of Chinese farms. As small-scale farming can involve many competitors, and hence increase the potential risk of vicious pricing. Nonetheless, participating in SFSCs can effective avoid this phenomenon and increase the farmers' profits in return.

Unlike the social and economic pillars, thecomparison of findings on theenvironmental pillar is rather distinct. While similar to the economic pillar, the improvements in the environmental sustainability of SFSCs are less evident. There are still some existing studies have found a close linkage between environmentalsustainability and SFSCs. For instance, several studies have found that SFSCs can effectively reduce energy consumption (Connelly et al., 2011; Hara et al., 2013; Cleveland et al., 2014; McClenachan et al., 2014; Forssell and Lankoski, 2015; Canfora, 2016; Sellitto et al., 2018). Meanwhile, Tasca et al. (2017) found thatthe abandon of disposable packing and industrial processing in direct distribution can effectively reduce environmental impacts by $20 \%$ to $48 \%$. Moreover, the improved biodiversity (Mastronardi et al., 2015;Berti and Mulligan, 2016; Rover et al., 2017) and the higher tendency to adopt environmental-friendly practices (Aubert and Enjolras, 2015; Forssell and Lankoski, 2015; Mundler and Laughrea, 2016) are also confirmed as the environmental benefits of SFSCs. However, during the pilot study, it was found that the interviewed Chinese farmers are almost unconscious about the environmental protection and have never considered this factor before. These farmers have never heard of environmental sustainability before and the vagueness in pesticides usage can also reflect their unconscious on this factor. Although these interviewed farmers have regularly changed their farming products, and maintained a relatively small food miles, their motivations are not concerning on the environmental protection. This phenomenon could be caused by the lack of relevant knowledge and governmental propaganda, as the guidance policy of the development of Chinese food supply system has been "pollution first and then elimination" (Tan, 2007). Thus, these interviewed farmers' unconscious on environmental protection could be easily interpreted.

\section{Conclusion}

This paper investigates the farmers' attitudes towards participating in SFSCs by conducting a field research in China. To ensure the significance of the findings, a pilot study was implemented in a city that possesses a mixed urban-rural geography, and belongs to the largest agricultural-export province in China. A medium-sized farmer market in this city was selected as the experiment venue for data collection. Eight farmers were randomly selected at the venue and each was interviewed with a semi-structured questionnaire. This pre-designated questionnaire consists of multiple open-ended questions that attempt to investigate their attitudes towards joining SFSCs from the three pillars of sustainability.

Through the analysis of collected data, it was found that the most prominent factors that motivate these farmers to participate in SFSCs are the direct communications with customers and fellow farmers; the increased profits of direct selling; and the close geographical distance between their farms and the market. While the farmers' opinions on these social and economic pillars of sustainability are essentially the same between the pilot study and existing studies, the major difference is with the environmental pillar. It was found that these interviewed Chinese farmers are unaware of the environment effects of farming, as they never heard of biodiversity and sustainable agriculture before. Meanwhile, their usages of pesticide are also mainly based on experience instead of following instructions. Moreover, although the interviewed Chinese farmers also enjoyed the social and economic benefits of SFSCs, it seems that their participation is more like 
a passive choice instead of spontaneous decision. This is mainly caused by the lack of relevant knowledge and governmental propaganda. Nonetheless, they still acknowledged their preference of selling at farmer market over directly selling to wholesalers.

Moreover, another interesting finding is the difference in farmers' demographic between the conducted research and existing studies. It was found that most Chinese farmers are younger females and older males, as younger males tend to work as migrant workers to earn extra income for supporting the family. Moreover, the average education level of Chinese farmers is lower than those of developed countries. The lack of sufficient education can be the underlying cause to the unawareness of sustainable agriculture and the misuse of pesticide.

Although the advantages of SFSCs are not widely recognised in China, it should be noted that some Chinese farmers have already participated in SFSCs to share its social and economic benefits. Moreover, the local government has shown an increasing interest of promoting farmer market in recent years. Therefore, it can be noted that with the increasing governmental support and guidance, more Chinese farmers will become aware of the benefits of joining SFSCs, and more participants can be expected in the near future.

\section{References}

Aubert, M., \& Enjolras, G. (2016). Do short food supply chains go hand in hand with environment-friendly practices? International Journal of Agricultural Resources, Governance and Ecology, 12(2), 189-213.

Balázs, B., Pataki, G., \& Lazányi, O. (2016). Prospects for the future Community supported agriculture in Hungary. Futures, 83, 100-111.

Bazzani, C., \& Canavari, M. (2013). Alternative agri-food networks and short food supply chains: A review of the literature. Economia Agro-Alimentare, 24,11-34.

Beckie, M. A., Kennedy, E. H.,\& Wittman, H. (2012). Scaling up alternative food networks: Farmers' markets and the role of clustering in western Canada. Agriculture and Human Values, 29(3),333-345.

Benedek, Z., Fertő, I., \& Molnár, A. (2017). Off to market: But which one? Understanding the participation of small-scale farmers in short food supply chains a Hungarian case study. Agriculture and Human Values, 35(2), 1-16.

Berti, G., \& Mulligan, C. (2016). Competitiveness of small farms and innovative food supply chains: The role of food hubs in creating sustainable regional and local food systems. Sustainability, 8(7), 616.

Bimbo, F., Bonanno, A., Nardone, G., \&Viscecchia, R. (2015). The hidden benefits of short food supply chains: Farmers' market density and body mass index in Italy. International Food and Agribusiness Management Review, 18(1),1-16.

Canfora, I. (2016). Is the short food supply chain an efficient solution for sustainability in food market?Agriculture and Agricultural Science Procedia, 8, 402-407.

Carrillo, B. (2004). Rural-Urban Migration in China: Temporary Migrants in Search of Permanent Settlement. PORTAL Journal of Multidisciplinary International Studies, 1(2),1-26.

Chen, J. Q., \& Zheng J. G. (2016). On farmers' educational problem in the construction of beautiful village: A case study of Jinjiang City. SHS Web of Conferences, 24, 02003.

Chiffoleau, Y., Millet-Amrani, S., \& Canard, A. (2016). From short food supply chains to sustainable agriculture in urban food systems: Food democracy as a vector of transition. Agriculture, 6(4), 57.

China Internet Information Center. (2001). China Through A Lens. Recuperado de https://www.china.org. cn/english/features/46344.htm

Cleveland, D. A., Müller, N. M., Tranovich, A. C., Mazaroli, D. N., \& Hinson, K. (2014). Local food hubs for alternative food systems: A case study from Santa Barbara Country, California. Journal of Rural Studies, 35, 26-36. 
Connelly, S., Markey, S., \& Roseland, M. (2011). Bridging sustainability and the social economy: Achieving community transformation through local food initiatives. Critical Social Policy, 31(2), 308-324.

Demartini, E., Gaviglio, A., \& Pirani, A. (2017). Farmers' motivation and perceived effects of participating in short food supply chains: Evidence from a North Italian survey. Agricultural Economics, 63(5), 204-216.

D'Amico, M., Giuseppe, D. V., \& Bracco, S. (2014). Direct sale of agro-food product: The case of wine in Italy. Quality-Access Success, 15, 247-253.

Elghannam, A., Escribano, M., \& Mesias, F. (2017). Can social networks contribute to the development of short supply chains in the Spanish agri-food sector? New Medit, 16(1),36-42.

Engelseth, P. (2016). Developing exchange in short local foods supply chains. International Journal on Food System Dynamics, 7(3), 229-242.

Falguieres, M., Kumar, V., Garza-Reyes, J. A., Kumari, A., Lim, M. K., \& Rocha-Lona, L. (2015). Investigating the impact of short food supply chain on emigration: A study of Valencia community in Spain. International Federation of Automatic Control, 48(3),2226-2232.

Forssell, S., \& Lankoski, L. (2015). The sustainability promise of alternative food networks: an examination through "alternative" characteristics". Agriculture and Human Values, 32(1), 63-75.

Giampietri, E., Finco, A., \& Giudice, T. (2016). Exploring consumers' behaviour towards short food supply chains. British Food Journal, 118(3), 618-631.

Giampietri, E., Verneau, F., Giudice, T., Carfora, V., \& Finco, A. (2018). A theory of planned behaviour perspective for investigating the role of trust in consumer purchasing decision related to short food supply chains. Food Quality and Preference, 64, 160-166.

Giarè, F., \& Giuca, S. (ed.) (2012).Farmers and short chain: Legal profiles and socio-economic dynamics. Rome: National Institute of Agricultural Economics.

Hara, Y., Tsuchiya, K., Matsuda, H., Yamamoto, Y., \& Sampei, Y. (2013). Quantitative assessment of the Japanese "local production for local consumption" movement: A case study of growth of vegetables in the Osaka city region. Sustainability Science, 8(4), 515-527.

Higgins, V., Dibden, J., \& Cocklin, C. (2008). Building alternative food networks: Certification, embeddedness and agri-environmental governance. Journal of Rural Studies, 24(1), 15-27.

Hinrichs, C. (2000). Embeddedness and local food systems: Notes on two types of direct agricultural market. Journal of Rural Studies, 16(3), 295-333.

Hinson, R. A., \& Bruchhaus, M. N. (2008). Consumer preferences for locally produced strawberries. Journal of Food Distribution Research, 39(3), 56-66.

Ilberz, B., \& Maye, D. (2005). Alternative (Shorter) Food supply chain and specialist livestock products in the Scottish-English borders. Environment and Planning, 37, 823-844.

Jones, P., \& Bhatia, R. (2011). Supporting equitable food systems through food assistance at farmers' markets. American Journal of Public Health, 101(5), 781-783.

Kneafsey, M., Venn, L., Schmutz, U., Trenchard, L., Eyden-Woods, T., Bos, E., ... Blackett, M. (2013).Short food supply chains and local food systems in the EU. A state of play of their socio-economic characteristics. Luxembourg: Publications Office of the European Union.

Kumar, V., Wang, M., Kumari, A., Akkaranggoon, S., Garza-Reyes, J. A., Neutzling, D., \& Tupa, J. (2018). Exploring short food supply chains from Triple Bottom Line lens: A comprehensive systematic review. Paper presented at Proceedings of the International Conference on Industrial Engineering and Operations Management, Bangkok, Thailand.

Leiper, C., \& Sather, A. K. (2017). Co-creating an alternative: The moral economy of participating in farmers' markets. Local Environment, 22(7), 840-858. 
Llazo, E. (2014). Customer attitudes towards short food supply chain in Albania. Analele University of Bucharest, 8, 3-20.

Lu, M., \& Xia, Y. (2016). Migration in the People's Republic of China. Tokyo: Asian Development Bank Institute. Recuperado de: https://www.adb.org/publications/migration-people-republic-china

Macartney, J. (2008). China baby milk scandal spreads as sick toll rises to 13,000. Recuperado de https:// www.thetimes.co.uk/article/china-baby-milk-scandal-spreads-as-sick-toll-rises-to-13000-jlxdmrsk9qd

Marsden, T. K., Banks, J., \& Bristow, G. (2000). Food supply chain approaches: Exploring their role in rural development. Sociologia Ruralis, 40, 424-438.

Mastronardi, L., Marino, D., Cavallo, A., \& Giannelli, A. (2015). Exploring the role of farmers in short food supply chains: The case of Italy. International Food and Agribusiness Management Review, 18(2), 109130.

Marino, D., Mastronardi, L., Franco, S., De Gregorio, D., Cicatiello, C., \& Pancino, B. (2013). Farmers' markets, producer and consumer behaviour: Analysis of interactions with the metrics of sustainability. Paper presented at seventh Proceedings in System Dynamics and Innovation in Food Networks, Bonn, Germany. Doi: 10.18461/pfsd.2013.1320

McClenachan, L., Neal, B. P., Al-Abdulrazzak, D., Witkin, T., Fisher, K., \& Kittinger, J. N. (2014). Do community supported fisheries (CSFs) improve sustainability? Fisheries Research, 157, 62-69.

Migliore, G., Schifani, G., \& Cembalo, L. (2015). Opening the black box of food quality in the short supply chain: Effects of conventions of quality on consumer choice. Food Quality and Preference, 39, 141-146.

Mundler, P., \& Laughrea, S. (2016). The contributions of short food supply chains to territorial development: A study of three Quebec territories. Journal of Rural Studies, 45, 218-229.

O'Kane, G., \& Wijaya, S. Y. (2015). Contribution of farmers' markets to more socially sustainable food systems: A pilot study of a farmers' market in the australian capital territory (ACT), Australia. Agroecology and Sustainable Food Systems, 39(10), 1124-1153.

Renting, H., Marsden, T., \& Banks, J. (2003). Understanding alternative food networks: Exploring the role of short food supply chains in rural development. Environment and Planning A, 35, 393-411.

Roth, A. V., Tsay, A. A., Pullman, M. E., \& Gray, J. V. (2008). Unravelling the food supply chain: Strategic insights from China and the 2007 recalls. Journal of Supply Chain Management, 44(1), 22-39.

Rover, O. J., Gennaro, B. C., \& Roselli, L. (2017). Social innovation and sustainable rural development: The case of a Brazilian agroecology network. Sustainability, 9(1), 1-14.

Rural Planning Bureau of Xinxiang. (2017). Recuperado em http://www.xxghj.gov.cn/spectacle/Article. aspx?sid=60c81a6b95f3fe 59

Sage, C. (2003). Social embeddedness and relations of regard: Alternative 'good food' networks in southwest Ireland. Journal of Rural Studies, 19(1), 47-60.

Sellitto, M. A., Vial, L. A. M., \& Viegas, C. V. (2018). Critical success factors in Short Food Supply Chains: Case studies with milk and dairy producers from Italy and Brazil. Journal of Cleaner Production, 170, 1361-1368.

Sgroi, F., Trapani, A. M. D., Testa, R., \& Tudisca, S. (2014). The rural tourism as development opportunity or farms. The case of direct sales in Sicily. American Journal of Agricultural and Biological Sciences, 9(3), 407-419.

Smith, B. G. (2008). Developing sustainable food supply chains. Philosophical Transactions of the Royal Society B: Biological Sciences, 363(1492), 849-861.

Tan, X. W. (2007). The sustainability of food supply chain in China: Review and comment. Recuperado de https://www.china-europa-forum.net/bdfdoc-628_en.html 
Tasca, A. L., Nessi, S., \& Rigamonti, L. (2017).Environmental sustainability of agri-food supply chains: An LCA comparison between two alternative forms of production and distribution of endive in northern Italy. Journal of Cleaner Production, 140, 725-741.

Tudisca, S., Di Trapani, A. M., Sgroi, F., \& Testa, R. (2015). Socio-economic assessment of direct sales in Sicilian farms. Italian Journal of Food Science, 27(1), 101-108.

Watts, D., Leat, P., \& Revoredo-Giha, C. (2011). Local food activity in Scotland: Empirical evidence and research agenda. Regional Studies, 45(9), 1187-1205.

Zirham, M., \& Palomba, R. (2015). Innovation and multi functionality of female agriculture in the short food supply chain. four campania region case studies. Paper presented at seventh International Conference on Information and Communication Technologies in Agriculture, Food and Environment, Kavala, Greece.

Zirham, M., \& Palomba, R. (2016). Female agriculture in the short food supply chain: a new path towards the sustainability empowerment. Agriculture and Agricultural Science Procedia, 8, 372-377.

Submetido em: $23 / 11 / 2018$

Aprovado em: 20/03/2019 